Cerebrovasc Dis 2007;23:318-319

DOI: 10.1159/000098447

\section{Stroke Research Priorities for the Next Decade - A Supplement Statement on Intracranial Haemorrhage}

C. Stapf ${ }^{a}$, H.B. Van der Worp ${ }^{\mathrm{b}}$, T. Steiner ${ }^{\mathrm{c}}$, G.J.E. Rinkel ${ }^{\mathrm{b}}$, K. Nedeltchev ${ }^{\mathrm{d}}$, H. Mast ${ }^{\mathrm{e}}$, M. Dichgans ${ }^{\mathrm{f}}$, C. Cordonnier ${ }^{\mathrm{g}}$, M. Arnold ${ }^{\mathrm{d}}$, R. Al-Shahi ${ }^{\text {h }}$

a Department of Neurology, Hôpital Lariboisière, Paris, France; ${ }^{b}$ Department of Neurology, University Medical Center Utrecht, Utrecht, The Netherlands; ' ${ }^{\mathrm{D}}$ Department of Neurology, University of Heidelberg, Heidelberg, Germany; ${ }^{d}$ Department of Neurology, Inselspital, Bern, Switzerland; e Division of Stroke Medicine, Nottingham City Hospital, Nottingham, UK; ${ }^{f}$ Department of Neurology, Klinikum Grosshadern, Munich, Germany; ${ }^{9}$ Department of Neurology, Lille University Hospital,

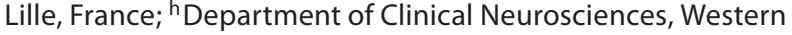
General Hospital, Edinburgh, UK

We were delighted by the recent initiative to define 'stroke research priorities for the next decade' [1]. The summary statement - reprints of which were kindly included in the congress material at last year's European Stroke Conference in Brussels clearly defines research priorities regarding cerebral reperfusion, delivery of stroke care, brain protection, recovery, cerebrovascular biology and stroke imaging.

Rather surprisingly, the 'representative view of the European scientific community' has overlooked intracranial haemorrhage altogether. This is somewhat counterintuitive, as intracranial haemorrhage (i.e. the various subsets of intracerebral, subarachnoid, intraventricular and subdural haemorrhage) carries an even higher morbidity and case fatality than ischaemic stroke and consequently represents a rising burden of illness within an increasingly aging European population. Despite $\sim 180,000$ new intracranial haemorrhage cases occurring in the EU every year, no specific treatment strategies are readily available (with the exception of subarachnoid haemorrhage), and no diagnostic standards for the detection of the various underlying causes have been established so far.

The aetiology, natural history and treatment options for nontraumatic intracerebral haemorrhage have attracted increasing interest over the last years. Many agree that the advances of modern imaging tools have clearly outdated the concept of so-called 'primary' intracerebral haemorrhage. Even cerebral 'small-vessel disease' may now be categorized into more specific subtypes (amyloid angiopathy, hypertensive arteriolopathy, genetic small-vessel disease, etc.) [2]. In an aging population, there is also increasing awareness about the impact of iatrogenic intracranial haemorrhage due to an increasing proportion of patients on oral anticoagulants and other antithrombotic medication [3]. The dynamics of acute haematoma growth and its impact on clinical outcome are increasingly better understood $[4,5]$, and specific treatment algorithms such as haemostatic therapy $[6,7]$ and acute surgical intervention $[8,9]$ are currently under investigation. Secondary endpoint analyses from recent clinical trials have underlined the beneficial effect of antihypertensive therapy below the threshold of currently recommended blood pressure values for both primary and secondary prevention of intracerebral haemorrhage $[10,11]$. Clearly, there is urgent need to support clinical trials to define blood pressure treatment targets, the timing of the achievement of such targets and related pharmacological protocols. On another scale, the constant technological improvement and widening availability of non-invasive brain imaging tools leaves physicians with a growing number of patients diagnosed as having potential sources of intracranial haemorrhage at a stage before any symptoms or actual bleeding have occurred. Unruptured aneurysms, unruptured brain arteriovenous malformations and clinically silent cavernous malformations - to name but a few - frequently create the clinical dilemma of whether and how to treat a patient depending on the balance between the potential risks and benefits of intervention versus our limited understanding of the natural histories of these lesions in general [12].

Clearly, more work needs to be done to improve prevention, treatment and outcome of intracranial haemorrhage [13]. A summary statement of a recent NINDS workshop may help to identify some research goals specific to intracerebral haemorrhage [14]. In addition, and as a supplement to the European 'stroke research priorities for the next decade', we offer the following global research objectives for intracranial haemorrhage.

- Develop and test diagnostic strategies for the detection of the various underlying congenital (arteriovenous malformations), genetic (cavernous malformations, familial aneurysms, etc.) and acquired (cerebral small-vessel disease, amyloid angiopathy, dural fistulas, etc.) causes of intracranial haemorrhage in a multicentre setting.

\section{KARGER}

(c) 2007 S. Karger AG, Basel

Fax +41613061234 E-Mail karger@karger.ch www.karger.com 
- Establish specific interventions in the management of acute intracerebral (blood pressure management, haemostatic therapy, invasive treatment strategies, etc.) and subarachnoid haemorrhage (timing and type of intervention for bleeding source, prevention and treatment of secondary complications, etc.) based on randomized controlled multicentre trials.

- Evaluate the risk/benefit ratio of invasive therapy for unruptured vascular pathologies (unruptured aneurysms, unruptured brain arteriovenous malformations, unruptured cavernous malformations, etc.) and the effectiveness of radiological follow-up in prospective epidemiological and randomized controlled clinical studies.

- Evaluate the risk/benefit ratio of invasive therapy for vascular pathologies underlying intracranial haemorrhage in the elderly (e.g. $15 \%$ of all subarachnoid haemorrhage patients are older than 70 years of age).

- Increase awareness of cognitive deficits and psychosocial problems after intracranial haemorrhage, develop facilities for information (for patients, family and employers) after discharge and help in coping with these problems [e.g. half the patients with subarachnoid haemorrhage are younger than 55 years of age, and only a minority resume their pre-morbid (working) activities].

- Optimize multidisciplinary diagnostic and therapeutic strategies for acute intracranial haemorrhage of any cause, including vascular neurology, diagnostic and interventional neuroradiology, neurosurgery, anaesthesiology and neuropsychology, to name but a few.

\section{References}

1 Meairs S, Wahlgren N, Dirnagel U, et al: Stroke research priorities for the next decade - a representative view of the European scientific community. Cerebrovasc Dis 2006;22:75-82.

2 Viswanathan A, Chabriat H: Cerebral microhemorrhage. Stroke 2006; 37:550-555.

3 Steiner T, Rosand J, Diringer M: Intracerebral hemorrhage associated with oral anticoagulant therapy: current practices and unresolved questions. Stroke 2006;37:256-262.

4 Flaherty ML, Haverbusch M, Sekar P, Kissela B, Kleindorfer D, Moomaw CJ, Sauerbeck L, Schneider A, Broderick JP, Woo D: Longterm mortality after intracerebral hemorrhage. Neurology 2006;66: $1182-1186$.

5 Davis SM, Broderick J, Hennerici M, Brun NC, Diringer MN, Mayer SA, Begtrup K, Steiner T; Recombinant Activated Factor VII Intracerebral Hemorrhage Trial Investigators: Hematoma growth is a determinant of mortality and poor outcome after intracerebral hemorrhage. Neurology 2006;66:1175-1181

6 Mayer SA, Brun NC, Begtrup K, Broderick J, Davis S, Diringer MN, Skolnick BE, Steiner T; Recombinant Activated Factor VII Intracerebral Hemorrhage Trial Investigators: Recombinant activated factor VII for acute intracerebral hemorrhage. N Engl J Med 2005;352:777-785.

7 You H, Al-Shahi R: Haemostatic drug therapies for acute primary intracerebral haemorrhage. Cochrane Database Syst Rev 2006;3: CD005951.

8 Mendelow AD, Gregson BA, Fernandes HM, Murray GD, Teasdale GM, Hope DT, Karimi A, Shaw MD, Barer DH; STICH investigators: Early surgery versus initial conservative treatment in patients with spontaneous supratentorial intracerebral haematomas in the International Surgical Trial in Intracerebral Haemorrhage (STICH): a randomised trial. Lancet 2005;365:387-397.

9 Minimally Invasive Surgery Plus rtPA for Intracerebral Hemorrhage Evacuation (MISTIE). http://www.clinicaltrials.gov/ct/show/ NCT00224770.
10 Chapman N, Huxley R, Anderson C, Bousser MG, Chalmers J, Colman S, Davis S, Donnan G, MacMahon S, Neal B, Warlow C, Woodward M; Writing Committee for the PROGRESS Collaborative Group: Effects of a perindopril-based blood pressure-lowering regimen on the risk of recurrent stroke according to stroke subtype and medical history: the PROGRESS Trial. Stroke 2004;35:116-121.

11 Qureshi AI, Mohammad YM, Yahia AM, Suarez JI, Siddiqui AM, Kirmani JF, Suri MF, Kolb J, Zaidat OO: A prospective multicenter study to evaluate the feasibility and safety of aggressive antihypertensive treatment in patients with acute intracerebral hemorrhage. J Intensive Care Med 2005;20:34-42.

12 Stapf C: Endovascular management of unruptured intracranial aneurysms: the dawn of a multidisciplinary treatment paradigm. J Neurol Neurosurg Psychiatry 2006;77:e1.

13 The European Stroke Initiative (EUSI) Writing Committee, Writing Committee for the EUSI Executive Committee: Recommendations for the diagnosis and management of intracranial haemorrhage. Cerebrovasc Dis 2006;22:294-316.

14 NINDS ICH workshop participants: Priorities for clinical research in intracerebral hemorrhage. Stroke 2005;36:e23-e41.

Christian Stapf, MD

Department of Neurology, Hôpital Lariboisière

2, Rue Ambroise Paré

FR-76475 Paris Cedex 10 (France)

Tel. +331 4995 2697, Fax +33 149952596

E-Mail christian.stapf@lrb.aphp.fr

Cerebrovasc Dis 2007;23:319-320

DOI: $10.1159 / 000098448$

\section{Priorities for European Stroke Research - Scope and Context}

\section{Reply to the Letter by Stapf et al.}

\author{
S. Meairs ${ }^{\mathrm{a}}$, N. Wahlgren ${ }^{\mathrm{b}}$ \\ on behalf of the participants of the European Stroke Workshop \\ a Department of Neurology, Faculty of Medicine Mannheim, \\ University of Heidelberg, Mannheim, Germany; ${ }^{\text {b Stroke }}$ \\ Research Unit, Department of Neurology, Karolinska Hospital, \\ Stockholm, Sweden
}

The participants of the European Stroke Workshop wish to thank the authors for their initiative to provide recommendations for future research goals in the field of intracerebral hemorrhage [1]. The clinical studies that are outlined by this group of stroke researchers are all valuable and deserve our full support.

It is important to understand that our paper on stroke research priorities [2] should not be interpreted as an all-encompassing statement. The publication rather summarizes the key issues that were discussed at the Stroke Workshop in Brussels, which was organized by the European Commission. This event included a talk by the Director of Health Research, Dr. Octavi Quintana Trias, on the goals of the upcoming Seventh Framework Programme. Coordinators of recent stroke-related projects funded by the European Union (STROKEGENE, UMEDS, MOLSTROKE and EUROCLOT) were invited to summarize the high- 